NBER WORKING PAPER SERIES

RESEARCH AND DEVELOPMENT AND

INTRAINDUSTRY SPILLOVERS:

AN EMPIRICAL APPLICATION

OF DYNAMIC DUALITY

Jeffrey I. Bernstein

M. Ishaq Nadiri

Working Paper No. 2002

NATIONAL BUREAU OF ECONOMIC RESEARCH

1050 Massachusetts Avenue

Cambridge, MA 02138

August 1986

The research reported here is part of the NBER's research program in Productivity. Any opinions expressed are those of the authors and not those of the National Bureau of Economic Research. 
Working Paper \#2002

August 1986

\section{Research and Development and Intraindustry Spillovers: \\ An Empirical Application of Dynamic Duality}

\section{ABSTRACT}

In this paper we estimate a model of production and investment based on the theory of dynamic duality and are particularly interested in the effects of $R \& D$ spillovers and in calculating the social and private rates of return. We identify and estimate three effects associated with the intraindustry R\&D spillover. First, costs decline as knowledge expands for the externality-receiving firms. Second, production structures are affected, as factor demands change in response to the spillover. Third, the rates of capital accumulation are affected by the R\&D spillover. These cost-reducing, factor-biasing and capital adjustment effects of the spillover are estimated for four industries.

The existence of $R \& D$ spillovers implies that the social and private rates of return to $R \& D$ capital differ. We estimate that the social return exceeds the private return in each industry. However, there is significant variation across industries in the differential between the social and private rates of return.

Jeffrey I. Bernstein Department of Economics Carleton University Ottawa, Ontario Canada K1S 5B6
M. Ishaq Nadiri Department of Economics New York University 269 Mercer Street, 7th floor New York, N.Y. 10003 


\section{Introduction ${ }^{*}$}

In many industries firms undertake research and development (R\&D) investment in order to develop new products or new processes. A feature of $R \& D$ investment that distinguishes it from other forms of investment is that the firm which will do the investing is not often able to exclude others from freely obtaining the benefits from its R\&D projects. The benefits from R\&D investment spill over to other firms in the economy, although the recipient firms have not paid for the use of the knowledge generated by the $R \& D$ activity.

The significance of spillovers in modeling and estimating the effects of R\&D investment has been emphasized by Griliches (1979). Recent theoretical work [see Reinganum (1981), and Spence (1984)] has analyzed the implications of R\&D spillovers in terms of a dynamic model of industry conduct and performance. In particular, Spence has shown that through spillovers a firm's $R \& D$ investment reduces production costs of rival firms. Thus the industrywide cost-reduction effect of R\&D investment is enhanced. Simultaneously, however, because spillovers generate free-rider problems, a firm's incentive to undertake R\&D activity is diminished.

The trade-off between the cost-reducing (or productivity) effect and the incentive effect of $R \& D$ investment may be exaggerated. Mowery (1983) and Nelson (1982) have argued that in order for firms to be able to use the freely available knowledge they may have to invest in $R \& D$. In other words, firms must have their own laboratories and staffs of scientists and engineers in order to incorporate the knowledge obtained through spillovers into their own production process. This has been shown by Cohen and Levinthal (1986) to imply 
that availability of spillovers also provides an incentive for a firm to undertake its own $R \& D$ investment, and can lead to an increase in industry $R \& D$ capital.

There has been very little empirical work devoted to the examination of the cost-reducing and incentive effects of R\&D spillovers. Evenson and Kislev (1973) estimated the productivity effect of $R \& D$ spillovers in wheat and maize for a cross section of countries. They concluded that borrowed knowledge caused a strong and persistent increase in crop yields. Levin and Reiss (1984) found that spillovers had a small but statistically significant effect in reducing average production costs for a cross section of manufacturing industries. Jaffe (1984) also estimated the productivity effect of spillovers. He found for a cross section of firms operating in various manufacturing industries that total factor productivity grew factor in response to spillovers.

The purpose of this paper is to develop and estimate a dynamic model incorporating intraindustry R\&D spillovers in order to investigate both the cost-reducing and incentive effects of these spillovers. The emphasis is on the manner by which production and investment decisions are influenced by $R \& D$ spillovers. In particular, estimates are obtained for the spillovers effects on the demands for R\&D and physical capital, as well as on variable and average costs of production.

The framework for this empirical work is the adjustment cost model of investment and factor demands. The approach is based on the theory of dynamic duality [see Rockafeller (1970), Benveniste and Scheinkman (1979), McClaren and Cooper (1980), and Epstein (1981)] because of the ease by which closed 
form solutions are obtained in dynamic models containing more than one quasifixed factor of production. It is assumed that a firm minimizes intertemporally expected production costs subject to a technology which includes adjustment costs associated with the quasi-fixed inputs (physical and knowledge capital), along with the spillovers emanating from R\&D capital of rival firms. Indeed it is the existence of these spillovers which distinguishes investment in plant and equipment from R\&D capital accumulation.

The paper is organized as follows: Section 2 describes the theoretical development of our model. The model is characterized by dynamic duality and includes R\&D spillovers. Section 3 contains the empirical specification of the model, a description of the data, and the estimates for the chemical, petroleum, machinery and instrument industries. Section 4 highlights the effects of $R \& D$ spillovers on production costs and the structure of production in both the short and long-runs. The next section contains the development and estimates of the social rate of return to R\&D capital for each industry. The last section contains our summary and conclusions. 


\section{The Theoretical Mode1}

R\&D spillovers are embodied in the technology of a firm which can be represented by

$$
y(t)=F\left(K_{p}(t), L(t), K_{r}(t), \theta X_{r}(t), I_{p}(t), I_{r}(t)\right)
$$

where $y(t)$ is the output flow, $K_{p}(t)$ is the physical capital service flow, $L(t)$ is the variable factor service flow, and $K_{r}(t)$ is the $R \& D$ capital service flow. The R\&D spillover is given by the variable $X_{r}(t)$, which is the R\&D capital service flow of other firms in the economy. Indeed, $X_{r}(t)=\Sigma_{f} K_{r}^{f}(t)$, where the summation is taken over all firms other than the one whose technology is represented by equation (1). The parameter $\theta$ captures the extent to which $R \& D$ capital is appropriable. If $\theta=0$ then $R \& D$ capital is completely appropriable and there are no spillovers; if $\theta=1$ then $R \& D$ capital is completely inappropriable and all knowledge is common; and if $0<\theta<1$, then there is incomplete appropriability.

The presence of investment, which is given by $I_{i}(t), i=p$ (physical) and $i=r(R \& D)$, in the specification of the technology implies that there are internal adjustment costs associated with changes in the level of the capital inputs (i.e. the quasi-fixed factors). These adjustments costs are measured in terms of foregone output [see Treadway (1971, 1974), Mortensen (1973) and Epstein (1981)]. Thus, with the production function denoted by $F$, increases in investment decrease output at a decreasing rate. However, increases in the variable, physical and $R \& D$ capital inputs increase output at a decreasing rate. $^{1}$ 
There are three effects associated with the R\&D spillover. First, from the production function given the inputs and investment, changes in the spillover generate changes in the quantity of output. This is the productivity effect. Second, given input levels and the investment rates changes in the R\&D spillover cause factor substitution. Indeed, the variable factor, physical capital and $R \& D$ capital may be complements or substitutes to the spillover. It is important to note that not only R\&D capital responds to the spillover, but in principle each factor of production can be affected by knowledge obtained from other firms in the economy. In the language of the technological change literature, changes in the $R \& D$ spillover cause factor biases, which may be either factor using or factor reducing. ${ }^{2}$

Because the technology incorporates adjustment costs, there is a third effect. Given output and factor quantities in the production function, changes in the R\&D spillover cause quasi-fixed factor adjustment as the rates of investment change. Thus the dynamic nature of the model implies that the incentive effect associated with the $R \& D$ spillover can be attributed to two . sources: changes in factor demands and changes in quasi-fixed factor accumulation.

The specification of the R\&D spillover embodied in technology is quite general and encompasses the specifications found in the theoretical literature. Reinganum (1981) and Spence (1984) assume that a firm's own R\&D capital is a perfect substitute for borrowed $R \& D$ capital. Thus in the present context $A_{r}=K_{r}+\theta X_{r}$ enters the production function where $A_{r}$ is the firm's R\&D capital which consists of its own and borrowed knowledge stocks denoted by $\mathrm{K}_{\mathrm{r}}$ and $\theta \mathrm{X}_{\mathrm{r}}$ respectively. Cohen and Levinthal (1986) assume that 
$A_{r}=K_{r}+\gamma\left(K_{r}\right) \theta \mathrm{X}_{r}$ where $\gamma$ represents the firm's knowledge absorption function which is increasing at a decreasing rate as the firm's own R\&D capital expands and $0<\gamma\left(K_{r}\right)<1$. In their model own and borrowed R\&D capital are not perfect substitutes, but the rate of substitution (all other things constant in the production function) between own and borrowed R\&D capital is independent of both the production technology and all non-R\&D capital factors of production. The rate of substitution depends only on the knowledge absorption function and the size of borrowed R\&D capital. However, in our model, we have generalized the factor substitution possibilities: own and borrowed R\&D capital may be substitutes or complements and the rate of substitution depends on the nature of the technology, all factors of production and rates of investment.

The accumulation of physical and R\&D capital stocks is governed by

$$
\dot{\mathrm{K}}_{i}=\mathrm{I}_{i}-\boldsymbol{\delta}_{\mathrm{i}} \mathrm{K}_{\mathrm{i}}, \quad \quad \mathrm{i}=\mathrm{p}, \mathrm{r}
$$

where $0 \leq \delta_{i} \leq 1, \quad i=p, r$ are the fixed rates of depreciation of the two types of capital stocks. ${ }^{3}$

The cost of the variable factor, of purchasing physical capital and of developing knowledge capital are

$$
c=G\left(K_{p}, K_{r}, \theta X_{r}, I_{p}, I_{r}, y\right)+p_{p} I_{p}+p_{r} I_{r}
$$

where $c$ are normalized (by the variable factor) costs, $p_{i}(i=p, r)$ is the normalized (or relative) investment price and $G$, the variable factor require- 
ments function, is derived by inverting the production function (denoted by $F$ in equation (1)).

The objective of the firm in any base period, with given relative prices, output, and other firms' knowledge capital, is to minimize the present value of costs over an infinite horizon by selecting the rates of investment subject to the process of capital accumulation. Current relative prices, output and $R \& D$ capital of other firms are expected to persist indefinitely. As the base period changes and new magnitudes of these variables are observed, the firm revises its expectations and its plans. Hence only at the base period is the plan actually carried out.

The firm's problem can be written as

$$
\min _{\left(I_{p}, I_{r}\right)} \int_{0}^{\infty} e^{-\rho t}\left[G\left(K_{p}, K_{r}, \theta X_{r}, I_{p}, I_{r}, y\right)+w_{p} K_{p}+w_{r} K_{r}\right] d t
$$

subject to equation set (2) with positive and given initial capital stocks, $\mathrm{K}_{\mathrm{i}}(0)=\mathrm{K}_{\mathrm{i}}^{0}>0, \quad \mathrm{i}=\mathrm{p}, \mathrm{r} .{ }^{4}$ The prices $\mathrm{w}_{i}=\mathrm{p}_{\mathrm{i}}\left(\rho+\delta_{i}\right), \quad \mathrm{i}=\mathrm{p}, \mathrm{r}$ are the relative rental rates of the capital stocks, and $\rho$ is the discount rate. ${ }^{5}$

Rather than solve the primal problem given by (4), we can approach the problem from the dynamic dual by defining the minimized present value of normalized costs as $J\left(\mathrm{~K}_{\mathrm{p}}, \mathrm{K}_{\mathrm{r}}, \theta \mathrm{X}_{\mathrm{r}}, \mathrm{w}_{\mathrm{p}}, \mathrm{w}_{\mathrm{r}}, \mathrm{y}\right)$, which [from Dreyfus (1965), Arrow and Kruz (1970) and Epstein (1981)] satisfies,

$$
\rho J\left(\mathrm{~K}_{\mathrm{p}}, \mathrm{K}_{r}, \theta \mathrm{X}_{r}, \mathrm{w}_{\mathrm{p}}, \mathrm{w}_{r}, \mathrm{y}\right)=\mathrm{G}\left(\mathrm{K}_{\mathrm{p}}, \mathrm{K}_{\mathrm{r}}, \theta \mathrm{X}_{\mathrm{r}}, \mathrm{I}_{\mathrm{p}}^{\mathrm{e}}, \mathrm{I}_{\mathrm{r}}^{\mathrm{e}}, \mathrm{y}\right)+\mathrm{w}_{\mathrm{p}} \mathrm{K}_{\mathrm{p}}+\mathrm{w}_{\mathrm{r}} \mathrm{K}_{\mathrm{r}}+\mathrm{J}_{\mathrm{p}}\left(\mathrm{I}_{\mathrm{p}}^{\mathrm{e}}-\delta_{\mathrm{p}} \mathrm{K}_{\mathrm{p}}\right)+\mathrm{J}_{\mathrm{r}}\left(\mathrm{I}_{\mathrm{r}}^{\mathrm{e}}-\delta_{r} \mathrm{~K}_{r}\right),
$$

where the superscript e denotes the equilibrium rates of investment and 
$\mathrm{J}_{i}=\partial \mathrm{J} / \partial \mathrm{K}_{\mathrm{i}}, \quad i=\mathrm{p}, \mathrm{r}$. The investment demand functions implied by equation (5) can be obtained by differentiating the latter with respect to the rental rates. Thus

$$
\rho \mathrm{J}_{\mathrm{w}}=\mathrm{K}+\mathrm{J}_{\mathrm{Kw}} \dot{\mathrm{K}}^{\mathbf{e}}
$$

where $\quad \mathrm{J}_{\mathrm{w}}=\left[\begin{array}{l}\partial \mathrm{J} / \partial \mathrm{w}_{\mathrm{p}} \\ \partial \mathrm{J} / \partial \mathrm{w}_{\mathrm{r}}\end{array}\right] \quad, \quad \mathrm{K}=\left[\begin{array}{c}\mathrm{K}_{\mathrm{p}} \\ \mathrm{K}_{\mathrm{r}}\end{array}\right]$

$$
\mathrm{J}_{\mathrm{KW}}=\left[\begin{array}{ll}
\partial^{2} \mathrm{~J} / \partial \mathrm{K}_{\mathrm{p}} \partial \mathrm{w}_{\mathrm{p}} & \partial^{2} \mathrm{~J} / \partial \mathrm{K}_{\mathrm{r}} \partial \mathrm{w}_{\mathrm{p}} \\
\partial^{2} \mathrm{~J} / \partial \mathrm{K}_{\mathrm{p}} \partial \mathrm{w}_{\mathrm{r}} & \partial^{2} \mathrm{~J} / \partial \mathrm{K}_{\mathrm{r}} \partial \mathrm{w}_{\mathrm{r}}
\end{array}\right] \quad \text {, and } \quad \dot{\mathrm{K}}^{\mathrm{e}}=\left[\begin{array}{c}
\mathrm{I}_{\mathrm{p}}^{\mathrm{e}}-\delta_{\mathrm{p}} \mathrm{K}_{\mathrm{p}} \\
\mathrm{I}_{\mathrm{r}}^{\mathrm{e}}-\delta_{\mathrm{r}} \mathrm{K}_{\mathrm{r}}
\end{array}\right]
$$

Solving equation set (6) for $\dot{\mathrm{K}}^{\mathrm{e}}$ and substituting into equation (5) yields the following set of three equations determining variable factor and investment demands,

$$
\begin{gathered}
\mathrm{L}^{\mathrm{e}}=\rho\left(\mathrm{J}-\omega^{\mathrm{T}} \mathrm{J}_{\mathrm{w}}\right)-\left(\mathrm{J}_{\mathrm{k}}^{\mathrm{T}}-\omega^{\mathrm{T}} \mathrm{J}_{\mathrm{KW}}\right) \dot{\mathrm{K}}^{\mathrm{e}} \\
\dot{\mathrm{K}}^{\mathrm{e}}=\mathrm{J}_{\mathrm{KW}}^{-1}\left(\rho \mathrm{J}_{\mathrm{w}}-\mathrm{K}\right), \\
\omega=\left[\begin{array}{c}
\mathrm{w}_{\mathrm{p}} \\
\mathrm{w}_{\mathrm{r}}
\end{array}\right], \quad \mathrm{J}_{\mathrm{K}}=\left[\begin{array}{c}
\mathrm{J}_{\mathrm{p}} \\
\mathrm{J}_{\mathrm{r}}
\end{array}\right], \text { and the superscript T }
\end{gathered}
$$

where

denotes vector transposition. The demand functions are dependent on the R\&D spillover because the latter affects the minimized present value of normalized costs (i.e. the value function $J$ ), which, in turn, is used to determine variable factor and investment demands. 


\section{Empirical Specification and Estimation}

In order to estimate equation set (7), the value function, J, must be specified and an error structure imposed. We hypothesize the following form for the value function,

$$
\begin{aligned}
\rho J\left(\mathrm{~K}_{\mathrm{p}}, \mathrm{K}_{\mathrm{r}}, \theta \mathrm{X}_{\mathrm{r}}, \mathrm{w}_{\mathrm{p}}, \mathrm{w}_{\mathrm{r}}, \mathrm{y}\right)= & \cdot 5 \mathrm{~b}_{0} \mathrm{y}+\cdot 5 \omega^{\mathrm{T}} \mathrm{B}_{\mathrm{wW}} \omega \mathrm{y}+\rho\left(\omega^{\mathrm{T}} \mathrm{A}_{\mathrm{wK}}^{-1}+\mathrm{a}^{\mathrm{T}}\right) \mathrm{K} \\
& +\left(\omega^{\mathrm{T}} \mathrm{A}_{\mathrm{wK}}^{-1} \mathrm{c}+\mathrm{a}_{0}\right) \mathrm{X}_{\mathrm{r}}+\omega^{\mathrm{T}} \mathrm{A}_{\mathrm{wK}}^{-1}(\mathrm{~h}+\mathrm{by})+\mathrm{h}_{0} .
\end{aligned}
$$

The parameters in the right side of (8) are given by the scalars $b_{0}, a_{0}, h_{0}$,

the vectors $a=\left[\begin{array}{l}a_{1} \\ a_{2}\end{array}\right], \quad c=\left[\begin{array}{l}c_{1} \\ c_{2}\end{array}\right], \quad h=\left[\begin{array}{l}h_{1} \\ h_{2}\end{array}\right], \quad b=\left[\begin{array}{l}b_{1} \\ b_{2}\end{array}\right]$,

and the matrices $B_{\mathrm{wW}}=\left[\begin{array}{ll}\mathrm{b}_{11} & \mathrm{~b}_{12} \\ \mathrm{~b}_{21} & \mathrm{~b}_{22}\end{array}\right], \quad A_{\mathrm{wK}}^{-1}=\left[\begin{array}{ll}a_{11} & a_{12} \\ a_{21} & a_{22}\end{array}\right]^{-1}$

The form of the value function is a generalized quadratic in the factor prices and linear in output, the capital stocks, and R\&D spillover. There are two attractive features of this functional form. First, the form of the function is preserved over the production, cost and value functions. In other words it is self-dual in the sense of Lau (1976). Second, the form is consistent with aggregation across production technologies, [for example across plants or across firms, see Epstein and Denny (1983)].

There are certain restrictions which the parameters in the model must satisfy. The parameters in the $B_{w w}$ matrix form a symmetric matrix which 
must be negative definite so that variable costs are strictly concave in the factor prices. Thus $b_{i j}=b_{j i}$ and $b_{i i}<0,\left(b_{i i} b_{j j}-b_{i j}^{2}\right)>0$ for $i, j=1,2, i \neq j$. The parameters in the matrix $A_{w K}$ must be such that the matrix characterizing capital adjustment, $\rho \mathrm{I}_{2}-\mathrm{A}_{\mathrm{wK}}$, is stable, where $\mathrm{I}_{2}$ is the $2 \times 2$ identity matrix. Thus, $0<\left(a_{i i}-\rho\right)<1$ and $\left(a_{i 1}-\rho\right)\left(a_{j j}-\rho\right)-a_{12} a_{21}>0$ for $i, j=1,2, i \neq j$. In addition, the vector a must be negative so that variable costs are decreasing in the capital stocks.

The corresponding investment and variable factor demand functions, implied by the specification of the value function, are found by substituting (8) and the appropriate derivatives into equation set (7),

$$
\begin{gathered}
\mathrm{L}^{\mathrm{e}}=\cdot 5 \mathrm{~b}_{0} \mathrm{y}-\cdot 5 \omega^{\mathrm{T}} \mathrm{B}_{w w} \omega \mathrm{y}+\mathrm{h}_{0}+\rho \mathrm{a}^{\mathrm{T}} \mathrm{K}-\mathrm{a}^{\mathrm{T}} \dot{\mathrm{K}}^{\mathrm{e}}+\mathrm{a}_{0} \mathrm{X}_{\mathrm{r}} \\
\dot{\mathrm{K}}^{\mathrm{e}}=\mathrm{A}_{w \mathrm{~W}} \mathrm{~B}_{w w} \omega \mathrm{y}+\mathrm{h}+\mathrm{by}+\mathrm{cX} \mathrm{X}_{\mathrm{r}}+\left(\rho \mathrm{I}_{2}-\mathrm{A}_{w \mathrm{~W}}\right) \mathrm{K} .
\end{gathered}
$$

From equation (9.1) we can see that the form of the value function does not restrict the degree of returns to scale for the production process, as equiproportional changes in output, the capital stocks, the rates of investment and the R\&D spillover do not lead to the same proportional change in the variable factor demand.

The R\&D spillover affects all the demand functions. Through the parameter $a_{0}$, the R\&D spillover directly affects the variable factor demand or normalized variable costs. ${ }^{6}$ In addition, the normalized variable costs are indirectly affected by the spillover through the investment demands. Each of the investment demands is also directly affected by the R\&D spillover through the parameters $c_{1}$ and $c_{2} \cdot{ }^{7}$ 
Notice that from (9.2) the net investment equations are of the flexible accelerator variety with

$$
\dot{\mathrm{K}}^{\mathrm{e}}=\mathrm{M}\left(\mathrm{K}-\mathrm{K}^{\mathrm{s}}\right)+\mathrm{cX}_{\mathrm{r}}
$$

where $\mathrm{M}=\rho \mathrm{I}_{2}-\mathrm{A}_{\mathrm{wK}}$ is the adjustment matrix given the rival firm's stock of knowledge and $\mathrm{K}^{\mathbf{s}}=-\left(\rho \mathrm{I}_{2}-\mathrm{A}_{\mathrm{wK}}\right)^{-1} \mathrm{~A}_{\mathrm{wK}}\left(\mathrm{B}_{\mathrm{wW}} \omega \mathrm{y}+\mathrm{h}+\mathrm{by}\right)$. The vector $\mathrm{K}^{\mathrm{s}}$ denotes the stationary or long-run level of the capital stocks when there is no effect of the R\&D externality on net investment (so that $c=0$ ). In this situation investment is governed by the traditional accelerator. However, the R\&D spillover may still be present, since it is possible for $a_{0} \neq 0$. If $c=0$ and $a_{0} \neq 0$ then the R\&D spillover has a cost-reducing or productivity effect but there is no adjustment effect associated with the capital inputs. If there are capital adjustments caused by the R\&D spillover then $c \neq 0$ and the longrun vector of capital stocks is

$$
\mathrm{K}^{\ell}=\mathrm{K}^{\mathrm{s}}-\mathrm{M}^{-1} \mathrm{cX}
$$

The difference between $K^{\ell}$ and $K^{s}$, given the adjustment matrix $M$, depends on the extent to which the long-run capital stocks are complements to $\left(c_{i}>0\right.$, $i=1,2)$ or are substitutes for $\left(c_{i}<0, i=1,2\right)$ the $R \& D$ spillover.

The adjustment path (given by (10)) for any type of capital stock depends on three elements. First, net investment for the $i^{\text {th }}$ capital stock depends on the magnitude of the $i^{\text {th }}$ stock through $\rho-a_{i i}$. Second, net investment of $i$ depends on its complementarity to or substitutability with the $j^{\text {th }}$ capital stock through $-a_{i j}$. Third, the path is governed by the complementarity to or substitutability with the R\&D spillover, which is given by $c_{i}$. 
Equation set (9) is our preferred specification. The equations are nonlinear in the parameters, with parameter restrictions within and across equations. Error terms reflecting optimizing and measurement errors are appended to equation set (9). These error terms are $u^{T}=\left(u_{\ell}, u_{p}, u_{r}\right)$ which are assumed to be jointly normally distributed, with zero mean, $E(u)=0$, and with positive definite symmetric covariance matrix, $E\left(u^{T}\right)=\Omega \otimes I_{N}$, where $\Omega$ is a $3 \times 3$ matrix and the subscript $N$ represents the number of observations. ${ }^{8}$ Equation set (9) can be estimated by the nonlinear maximum likelihood estimator. In order to estimate the system we take a discrete approximation with $\dot{\mathrm{K}}^{\mathrm{e}}=\mathrm{K}(\mathrm{t})^{\mathrm{e}}-\mathrm{K}(\mathrm{t}-1), \mathrm{K}=\mathrm{K}(\mathrm{t}-1)$ and $\mathrm{X}_{\mathrm{r}}=\mathrm{X}_{\mathrm{r}}(\mathrm{t}-1)$, so that equations (9.1) and (9.2) become

$$
\begin{aligned}
L^{e}(t) / y(t)= & \cdot 5 b_{0}-5 b_{11} w_{p}^{2}(t)-\cdot 5 b_{22} w_{r}^{2}(t)-b_{12} w_{p}(t) w_{r}(t) \\
& +h_{0} / y(t)+a_{1}(1+\rho) K_{p}(t-1) / y(t)+a_{2}(1+\rho) K_{r}(t-1) / y(t) \\
& -a_{1} K_{p}^{e}(t) / y(t)-a_{2} K_{r}^{e}(t) / y(t)+a_{0} X_{r}(t-1) / y(t)+u_{\ell}(t)
\end{aligned}
$$

$$
\begin{aligned}
\mathrm{K}_{i}^{\mathrm{e}}(t) / \mathrm{y}(t)=\left(\mathrm{a}_{11} \mathrm{~b}_{i 1}+\mathrm{a}_{i j} \mathrm{~b}_{1 j}\right) \mathrm{w}_{i}(t)+\left(\mathrm{a}_{1 i} \mathrm{~b}_{i j}+\mathrm{a}_{i j} \mathrm{~b}_{j j}\right) \mathrm{w}_{j}(t) \\
\quad+\mathrm{h}_{1} / \mathrm{y}(t)+\mathrm{b}_{i}+\left(1+\rho-\mathrm{a}_{i j}\right) \mathrm{K}_{i}(t-1) / y(t)-a_{i j} \mathrm{~K}_{j}(t-1) / y(t) \\
\quad+c_{i} \mathrm{X}_{r}(t-1) / y(t)+u_{i}(t), \quad i, j=p, r, \quad i \neq j .
\end{aligned}
$$

The data used to estimate equation set (12) pertain to the chemical (SIC 28), petroleum (SIC 29), machinery (SIC 35), and instruments (SIC 38) industries. The time period of the sample is 1965-1978 for each industry. In 
addition there are 22 firms in the chemical industry, 5 firms in the petroleum industry, 13 firms in the machinery, and 15 firms for instruments. The model has been estimated for each industry and the time series and cross section data were pooled. The majority of the data was obtained from the National Bureau of Economic Research's R\&D Master file [see Cummins, Hall and Laderman (1982)]. Each firm's R\&D capital (exclusive of the spillover, which is referred to as $\mathrm{K}_{\mathrm{r}}$ ) was constructed by the declining balance formula for depreciation with an assumed depreciation rate of $0 \cdot 1$. The initial level of R\&D capital was obtained by dividing constant dollar R\&D expenditures by the sum of the depreciation rate, and the average rate of growth of output. Output $(y)$ is sales divided by the producer price index defined at the two digit SIC level. The latter was obtained from the Bureau of Labor Statistics. With the R\&D capital for each firm, we were able to measure the R\&D capital relating to rivals in the industry confronting each firm (this is variable $\mathrm{X}_{\mathrm{r}}$ ). Physical capital $\left(\mathrm{K}_{\mathrm{p}}\right)$ is the deflated net plant value from the Master File, while the variable factor (L) is the constant dollar value of operating costs. The depreciation rate for physical capital was .0595 for chemicals, .0713 for petroleum, .0707 for machinery and .0560 for instruments. These depreciation rates were calculated by summing over time depreciation allowances divided by the gross plant and equipment and then dividing this sum by the number of time periods. Depreciation allowances were obtained from the Master File. The physical capital price index $\left(\mathrm{p}_{\mathrm{p}}\right)$ is the national fixed investment deflator and the $R \& D$ capital price index $\left(p_{r}\right)$ was developed at the NBER [see Cummins, Hall and Laderman (1982, p. 15)]. The discount rate $(p)$ is the mean of the preferred divided rate for medium risk companies (see Cummins, Hal1 and Laderman (1982, p. 15)], which is .0719. 
The estimation results are presented in Tables 1 and 2 . The system of equations converged with a criterion of $\cdot 001$, and although we cannot be sure we are at a global maximum of the likelihood function, different initial values of the parameters led to virtually identical estimates. The estimates satisfy the optimality conditions since $b_{i i}<0,\left(b_{i i} b_{j j}-b_{i j}^{2}\right)>0$, $0<a_{i i}<1+\rho,\left[\left(a_{i i}-\rho\right)\left(a_{j j}-\rho\right)-a_{i j} a_{j i}\right]>0$ and $a_{i}<0$, for $i, j=1,2$.

Before we investigate the effects of the R\&D spillover on the structure of production, costs and rates of return, it is interesting to discuss the adjustment process for physical and R\&D capital. The speed at which physical capital adjusts is given by $\left(a_{11}-\rho\right)$, when the stock of knowledge capital is fixed. We can refer to this adjustment process as the own effect. The estimation results show that 42 percent of the adjustment for physical capital in the chemical industry occurs within a single year. This means that it takes 2.4 years for physical capital to adjust. Similarly for the petroleum, machinery and instrument industries physical capital adjusts in 3.1 years, 2.4 years, and 2.9 years respectively.

The speed of the own adjustment process for R\&D capital is given by the value of $\left(a_{22}-\rho\right)$ when physical capital is fixed. For the chemical, petroleum, machinery and instrument industries, we find that R\&D capital adjusts in 2.6 years, 2.3 years, 2 years, and 2.5 years respectively. Clearly the adjustment speeds with respect to the own effects are quite similiar for both capital stocks in all four industries.

There are also cross effects associated with the adjustment processes of the capital stocks. These effects are given by $-a_{i j}, i \neq j$. The coefficient $-a_{12}$ relates to the adjustment in physical capital associated with changes in 
Table 1

Estimation Results

for

Chemical and Petroleum Industries

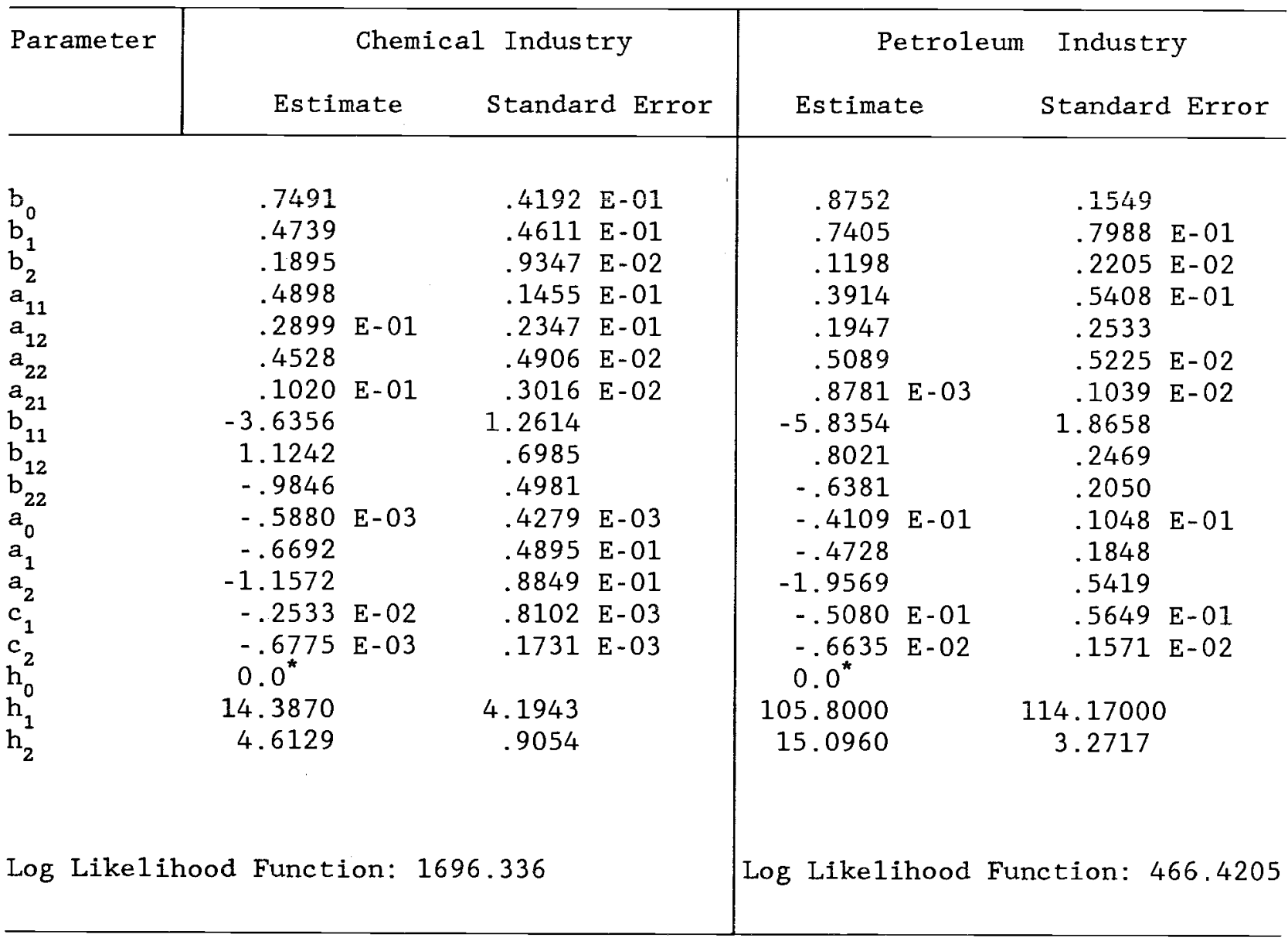

* Not estimated; constrained to be zero. 
Table 2

Estimation Results

for

Machinery and Instruments Industries

\begin{tabular}{|c|c|c|c|c|c|}
\hline \multirow[t]{2}{*}{ Parameter } & \multicolumn{2}{|c|}{ Machinery Industry } & \multicolumn{3}{|c|}{ Instruments Industry } \\
\hline & Estimate & Standard Error & Estimate & \multicolumn{2}{|c|}{ Standard Error } \\
\hline $\begin{array}{l}b_{0} \\
b_{1} \\
b_{2} \\
a_{11} \\
a_{12} \\
a_{22} \\
a_{21} \\
b_{11} \\
b_{12} \\
b_{22}^{12} \\
a_{0} \\
a_{1} \\
a_{2} \\
c_{1} \\
c_{2} \\
h_{0} \\
h_{1} \\
h_{2}\end{array}$ & $\begin{array}{rl}.9895 \\
.5209 \\
.1248 \\
.4891 \\
.1206 \\
.5776 \\
-.5979 \quad \mathrm{E}-02 \\
-3.6088 \\
.6381 \\
-.4806 \\
-.8779 & \mathrm{E}-03 \\
-.8198 & \\
-.3122 & \\
.1109 & \mathrm{E}-02 \\
-.6587 & \mathrm{E}-03 \\
0.0 * & \\
-1.2697 & \\
1.2204 & \end{array}$ & 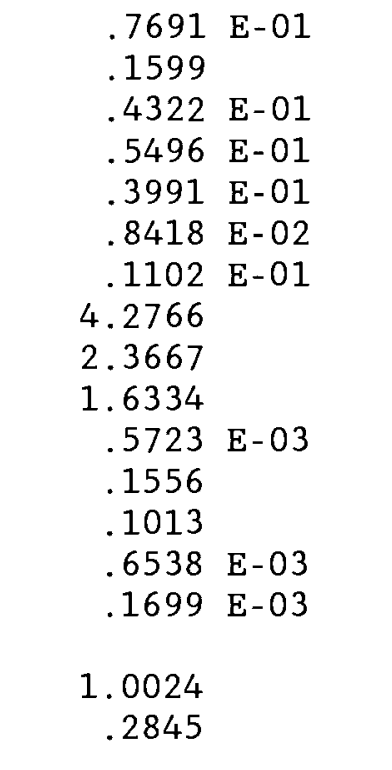 & $\begin{array}{rl}.6062 & \\
.4202 & \\
.1949 & \\
.4223 & \\
.7317 & \mathrm{E}-01 \\
.4749 & \\
-.2629 & \mathrm{E}-01 \\
-2.7608 & \\
.2575 & \\
-1.0733 & \\
-.2151 & \mathrm{E}-02 \\
-.5861 & \\
-.1036 & \\
-.4429 & \mathrm{E}-03 \\
-.2594 & \mathrm{E}-03 \\
-4.4331 & \\
.6765 & \\
.1045 & \end{array}$ & $\begin{array}{r}.5671 \\
.2723 \\
.1636 \\
.2366 \\
.2041 \\
.1228 \\
.1403 \\
1.7545 \\
1.2340 \\
.9094 \\
.1017 \\
.1409 \\
.1109 \\
.4409 \\
.2706 \\
2.3750 \\
1.0267 \\
.6300\end{array}$ & $\begin{array}{l}E-01 \\
E-01 \\
E-01 \\
E-01 \\
E-01 \\
E-01 \\
E-01\end{array}$ \\
\hline Log Likelil & od Function: & 521.7933 & Log Likelihood & Function: 1 & .001 .443 \\
\hline
\end{tabular}

* Not estimated; constrained to be zero. 
R\&D capital, and $-a_{21}$ defines the converse adjustment. Thus, for the chemical industry we find a deficient stock of R\&D capital (relative to its longrun level) causes the adjustment of physical capital to slow down by 2.9 percent in one year. Conversely, if physical capital is below its long-run level, then the speed of adjustment for R\&D capital to slow down by 1.0 percent in a single year. In the chemical industry the cross effects associated with the adjustment processes generate a complementarity, since a smaller stock of one type of capital slows down the speed of adjustment of the other stock.

The cross effects for the remaining three industries are quite distinct from the chemical industry. For petroleum a deficient R\&D capital stock causes the adjustment of physical capital to slow down by almost 20 percent. This effect is similiar in direction but significantly greater than that found for chemicals. However, physical capital does not affect the adjustment process of the R\&D stock in the petroleum industry.

In the machinery and instruments industries the results are quite similiar to each other. As for chemicals and petroleum, decreases in R\&D capital slow down the adjustment process for physical capital; 12 percent and 7 percent for machinery and instruments respectively. However, a decrease in physical capital actually speeds up the process of R\&D adjustment. In both industries the magnitudes are very small; slightly more than $\cdot 5$ percent for machinery and 2.5 percent for instruments. Hence, in all four industries the adjustment in R\&D capital has a complementary effect on the adjustment of physical capital, but the converse is not true. The complementarity implies that the accumulation of knowledge causes firms to invest in physical capital. 
However, investing in physical capital does not necessarily mean that firms undertake more R\&D capital accumulation. ${ }^{9}$

Changes in the R\&D spillover also affect the rates of investment of both quasi-fixed factors through the parameters $c_{1}$ and $c_{2}$. From Tables 1 and 2, we can observe that the estimates of these two parameters are very small. The estimates of $c_{2}$ are negative and consequently an increase in the R\&D spillover decreases the rate of accumulation of $R \& D$ capital. This result implies that the spillover is a substitute for a firm's own R\&D capital investment and so the firm can afford to divert resources away from the accumulation of its own $R \& D$ capital. The esitmates of $c_{1}$ are also negative for three out of the four industries. An increase in the R\&D spillover increases the rate of accumulation of physical capital only for the machinery industry. 


\section{R\&D Spillover Effects on Production}

R\&D spillovers cause average costs to decline and factor proportions to change for the spillover-receiving firms. These cost-reducing and factorbiasing effects of R\&D spillovers can be determined from equation set (12). Differentiating equation set (12) by $\mathrm{X}_{r}(t-1)$, yields, in elasticity form,

$$
\begin{aligned}
& e_{i \theta}^{s}(t)=c_{j} x_{r}(t-1) / K_{i}^{e}(t) \quad i=p, j=1, \quad \text { and } i=r, j=2 \\
& e_{l \theta}^{s}(t)=\left[a_{0} X_{r}(t-1)-a_{1} K_{p}^{e}(t) e_{p \theta}^{s}(t)-a_{2} K_{r}^{e}(t) e_{r \theta}^{s}(t)\right] / L^{e}(t)
\end{aligned}
$$

where $e_{j \theta}^{s}, \quad j=p, r, l$ are the short-run $R \& D$ spillover elasticities of factor demands (physical capital, R\&D capital and the variable factor). ${ }^{10}$

The spillover elasticity of average costs in the short-run is formed by noting that normalized costs of production are given by the right side of equation (5). Using the specification of the value function (equation (8)), we can write equation (5) as

$$
c^{s}(t)=L^{e}(t)+\omega^{T}(t)^{t} K(t-1)+\left[\omega^{T}(t) A_{w K}^{-1}+a^{T}\right)\left(K^{e}(t)-K(t-1)\right]
$$

where $c^{s}(t)$ are the short-run costs. ${ }^{11}$ Since $L^{e}(t)$ and $K^{e}(t)$ are functions of the R\&D spillover, by dividing through (14) by output and differentiating with respect to $x_{r}(t-1)$ we find that

$$
\begin{aligned}
e_{c \theta}^{s}(t)= & s_{\ell}^{s}(t) e_{l \theta}^{s}(t)+\left(w_{p}(t) a_{22}-w_{r}(t) a_{21}+a_{1} a_{w K}\right) s_{p}^{s}(t) e_{p \theta}^{s}(t) /\left(a_{w K} w_{p}(t)\right) \\
& +\left(w_{r}(t) a_{11}-w_{p}(t) a_{12}+a_{2} a_{w K}\right) s_{r}^{s}(t) e_{r \theta}^{s}(t) /\left(a_{w K} w_{r}(t)\right),
\end{aligned}
$$


where $e_{c \theta}^{s}$ is the spillover elasticity of average costs, $s_{i}^{s}, \quad i=\ell, p, r$ is the short-run cost share of the three factor demands and $a_{\mathrm{wK}}$ is the determinant of the matrix $\mathrm{A}_{\mathrm{wK}}$. The spillover elasticity of average costs consists of two parts. The first part relates to the effect of the spillover on average variable costs and the second to the effect of the spillover on the adjustment costs per unit of output. The latter component is divided into the adjustment costs associated with each of the two quasi-fixed factors.

The results for the four short-run elasticities are presented in Table 3. For each industry, we observe that the short-run demand for R\&D capital decreases in response to an increase in the R\&D spillover. Thus the spillover is $R \& D$ capital-reducing (or saving). In other words the spillover is a substitute for a firm's own R\&D capital. The elasticities are quite small however. The spillover is also physical capital-reducing for three of the industries. In the machinery industry the spillover is physical-capital using. As for $R \& D$ capital, the spillover elasticities for physical capital are highly inelastic. In the short-run both variable costs and average costs decline in response to a larger R\&D spillover. In each of the four industries the effects are smal1. Indeed average costs do not decrease by more than .2 percent for a 1 percent increase in the R\&D spillover.

The long-run effects of the R\&D spillover are derived from equation set (12), but with $K_{i}(t)=K_{i}(t-1), \quad i=p, r$, and differentiating with respect to $x_{r}(t-1)$. This yields

$$
e_{p \theta}^{l}(t)=\left(c_{1}\left(a_{22}-p\right)-c_{2} a_{12}\right) X_{r}(t-1) / K_{p}^{l}(t) H
$$


Table 3

Short-Run Effects of R\&D Spillovers

for

Chemica1, Petroleum, Machinery and Instruments Industries

(mean percent) ${ }^{*}$

\begin{tabular}{lccccc}
\hline & \multicolumn{5}{c}{ Industry } \\
\cline { 2 - 5 } Variable & Chemical & Petroleum & Machinery & Instruments \\
\hline R\&D Capital & $-.2559 \mathrm{E}-01$ & $-.3918 \mathrm{E}-01$ & $-.3229 \mathrm{E}-01$ & $-.9974 \mathrm{E}-02$ \\
Physical Capital & $-.4274 \mathrm{E}-01$ & -.4985 & $\mathrm{E}-01$ & $.4382 \mathrm{E}-01$ & $-.1233 \mathrm{E}-01$ \\
Variable Costs & -.1992 & -.2090 & $-.1076 \mathrm{E}-01$ & -.8288 E-01 \\
Average Costs & -.1030 & -.1740 & -.3007 E-01 & -.5286 E-01 \\
\hline
\end{tabular}

* Based on a 1 percent increase in the R\&D spillover. 


$$
e_{r \theta}^{\ell}(t)=\left(c_{2}\left(a_{11}-\rho\right)-c_{1} a_{21}\right) X_{r}(t-1) / K_{r}^{\ell}(t) H
$$

$$
e_{\ell \theta}^{\ell}(t)=\left(a_{0} X_{r}(t-1)+a_{1} \rho K_{p}^{\ell}(t) e_{p \theta}^{\ell}(t)+a_{2} \rho K_{r}^{\ell}(t) e_{r \theta}^{\ell}(t)\right) / L^{\ell}(t)
$$

$$
e_{c \theta}^{\ell}(t)=s_{\ell}^{\ell}(t) e_{\ell \theta}^{\ell}(t)+s_{p}^{l}(t) e_{p \theta}^{\ell}(t)+s_{r}^{l}(t) e_{r \theta}^{\ell}(t)
$$

where $e_{i \theta}^{\ell}, i=p, r, \ell, c$ is the long run spillover elasticity on physical capital, R\&D capital, the variable factor (or variable costs) and average costs respectively. Also, $\mathrm{H}=\mathrm{a}_{11} \mathrm{a}_{22}-\mathrm{a}_{12} \mathrm{a}_{21}$. The long-run spillover results are presented in Table 4. Not surprisingly the long-run spillover elasticities of the quasi-fixed factors are more elastic than in the short-run. In addition, the signs have not changed between the short and long-runs. Moreover in the long-run the elasticities for physical and R\&D capital are still highly inelastic. Variable and average costs also decrease in the long-run as the $R \& D$ spillover increases. The effects on variable and average costs are generally quite similar between the short and long-runs, and therefore are significantly inelastic in the long-run. 
Table 4

Long-Run Effects of R\&D Spillovers

for

Chemica1, Petroleum, Machinery and Instruments Industries (mean percent)*

\begin{tabular}{|c|c|c|c|c|}
\hline \multirow[b]{2}{*}{ Variable } & \multicolumn{4}{|c|}{ Industry } \\
\hline & Chemical & Petroleum & Machinery & Instruments \\
\hline R\&D Capital & $-.7430 \mathrm{E}-01$ & $-.7237 \mathrm{E}-01$ & -.1136 & -.3156 E-01 \\
\hline Physical Capital & $-.9861 \quad E-01$ & -.1353 & .8218 E-01 & $-.2465 E-01$ \\
\hline Variable Costs & -.1014 & -.2444 & $-.6072 E-01$ & -.1048 \\
\hline Average Costs & $-.9541 E-01$ & -.1766 & -.3502 E-01 & -.6493 E-01 \\
\hline
\end{tabular}

* Based on a 1 percent increase in the R\&D spillover. 


\section{The Social Rate of Return to R\&D Capital}

The existence of $R \& D$ spillovers implies that a wedge is created between the private and social rates of return to $R \& D$ capital. The derivation of the social rate of return for each industry can be derived from a program characterizing joint (in other words for all the firms in the industry) intertemporal cost minimization. For any industry the joint present value of normalized costs can be written as

$$
W(0)=\int_{0}^{\infty} e^{-\gamma t} \sum_{i=1}^{n}\left[G^{i}\left(K_{p}^{i}, K_{r}^{i}, \theta_{i} X_{r}^{i}, I_{p}^{i}, I_{r}^{i}, y^{i}\right)+p_{p} I_{p}^{i}+p_{r} I_{r}^{i}\right] d t
$$

where the superscript $i$ represents a firm in the industry and $\gamma$ is the discount rate for the industry. The problem is to minimize the right side of (17) by selecting the rates of investment for each firm subject to the capital accumulation process characterized by equation set (2). This is a relatively standard optimal control problem except there exists R\&D spillovers. The Euler equation for $R \& D$ investment is

$$
\left(\gamma+\delta_{r}\right)\left(p_{r}+\partial G^{1} / \partial I_{r}^{i}\right)-\left(\partial \dot{G}^{i} / \partial I_{r}^{i}\right)=-\left(\partial G^{i} / \partial K_{r}^{i}\right)-\Sigma_{j \neq 1} \partial G^{j} / \partial K^{i} \quad, \quad i=1, \ldots n .
$$

Equation (18) shows that the industry invests in $R \& D$ until the marginal cost of $R \& D$ capital for the $i^{\text {th }}$ firm (given by the left side of (18)) equals the marginal benefit. The latter is defined as the reduction in the ith firm's variable costs and the net reduction in the variable costs of every other firm in the industry as the ith firm's $R \& D$ capital is expanded.

Clearly, the industry's intertemporal cost minimization solution differs from the individual firm's solution because of the spillovers associated with 
the R\&D capital stocks. The spillover are externalities to the firm but they are internalized by the industry. Indeed, the ith firm's condition with respect to $R \& D$ investment implied by the problem in (4) is,

$$
\left(\rho+\delta_{r}\right)\left(P_{r}+\left(\partial G^{i} / \partial I_{r}^{i}\right)\right)-\left(\partial \dot{G}^{i} / \partial I_{r}^{i}\right)=-\left(\partial G^{i} / \partial K_{r}^{i}\right), \quad i=1, \ldots, n .
$$

Subtracting (19) from (18) to obtain the difference between the industry and firm solutions, we find that

$$
\gamma=\rho-\left[\Sigma_{j \neq i}\left(\partial G^{i} / \partial K_{r}^{i}\right) /\left(P_{r}+\left(\partial G^{i} / \partial I_{r}^{i}\right)\right], \quad i=1, \ldots, n .\right.
$$

Equation (20) shows that the social rate of return on R\&D capital in an industry (which is $\gamma$ ) differs from the private rate $(\rho)$ by the extent that a firm's R\&D capital reduces the costs of its rival firms throughout the industry. ${ }^{12}$ Clearly, if $\left(\partial G^{i} / \partial K_{r}^{i}\right)=0, \quad i \neq j, \quad i, j=1, \ldots, n$, then $\gamma=\rho$ and there would not be any wedge between the social and private rates of return.

In order to obtain values for the right side of (20), we need the variable factor requirement function based on the specification of the value function (denoted as equation (8)). The variable factor requirement function is given by (12.1). From equation (12.1), $\Sigma_{j \neq i}\left(\partial G^{i} / \partial K_{r}^{1}\right)=a_{0}(n-1)$ where $n$ is the number of firms in the industry. In addition, from (12.1), $\partial G^{i} / \partial I_{r}^{i}=-a_{2}$. Hence equation (20) becomes

$$
\gamma=\rho-a_{0}(n-1) /\left(p_{r}-a_{2}\right)
$$

Notice that since $a_{0}<0$, and $a_{2}<0$ then $\gamma>\rho$. R\&D spillovers cause the social rate of return on $R \& D$ capital to exceed the private rate of return. 
Table 5 shows the social rate of return on R\&D capital for each industry and percentage by which the social rate exceeds the private rate. The results vary significantly by industry. For the chemical and instrument industries, the R\&D spillover generates social rates of return which are 29 percent and 35 percent respectively greater than the private rate. However, in the petroleum industry the social return is substantially (76 percent) above the private return, while for machinery the spillover only generates a social return 9 percent above the private rate.

There have not been many empirical studies which have investigated the extent to which intraindustry $R \& D$ spillovers create a divergence between the social and private rates of return on R\&D capital. Jaffe (1985) has looked at spillovers for a cross section of manufacturing firms. Although his framework is quite different from the model in this paper, Jaffe estimated that the social return on $R \& D$ capital is 40 percent higher than would be the case in the absence of spillovers. Mansfield et al. (1977) conducted an analysis of a small group of major $R \& D$ projects and concluded that the social rate of return was 77 to 150 percent greater than the private return. The results in this paper relating to the deviation between the social and private rates of return are on average consistent with the Jaffe estimates and lower than those obtained by Mansfield and his colleagues. However, we also find that there are important industry variations regarding the extent to which the social return exceeds the private return in the context of intraindustry spillovers. 


\section{Table 5}

Social Rate of Return on R\&D Capital for

Chemical, Petroleum, Machinery and Instruments Industries

\begin{tabular}{lcc}
\hline Industry & Social Rate of Return* & $\begin{array}{c}\text { Percentage Difference Between } \\
\text { Social and Private Rates }\end{array}$ \\
\hline Chemical & .9276 E-01 & 29 \\
Petroleum & .1266 & 76 \\
Machinery & .7846 E-01 & 9 \\
Instruments & .9685 E-01 & 35 \\
\hline
\end{tabular}

* This column pertains to the mean social net of depreciation real rate of return. The private rate is $\rho=.0719$. 


\section{Summary and Conclusions}

In this paper we estimated a model of production and investment based on the theory of dynamic duality. The dynamics arose from the adjustment costs associated with the accumulation of both physical and R\&D capital stocks. The capital stocks were distinguished by the fact that the returns to R\&D investment were not perfectly appropriable, because spillovers were generated between firms from the process of R\&D capital accumulation.

There are a number of effects associated with the intraindustry R\&D spillover. First, costs decline as knowledge expands for the externality-receiving firms. Second, production structures are affected, as factor demands change in response to the spillover. Third, the rates of capital accumulation are affected by the R\&D spillover. These cost-reducing, factor-biasing and capital adjustment effects of the spillover were estimated for four industries. We found that the spillover decreased the rate of R\&D investment and was R\&D capital-reducing in all four industries. The same conclusion applied to physical capital in three of the four industries. In both the short and long-runs the quasi-fixed factor-biasing results were highly inelastic. In the short-run the range of decline in R\&D capital was .01 percent to .04 percent, while in the long-run the range was .03 percent to .11 percent. The decrease in physical capital was slightly more elastic with a range of .01 percent to .05 percent in the short-run and .03 percent to .14 percent in the long-run: In the machinery industry the demand for physical capital increased in response to the R\&D spillover. In the short-run the increase was .04 percent and in the long-run .08 . In addition both variable and average costs decreased in response to an increase in the R\&D spillover. 
However, in both the short and long-runs the cost-reducing effects were quite small. Indeed, the smallest decline in costs was .03 percent and the largest decrease was .18 percent as the intraindustry spillover increased by 1 percent.

The existence of R\&D spillovers implies that the social and private rates of return to $R \& D$ capital differ. We estimated that the social return exceeded the private return in each industry. However, there was significant variation across industries in the differential between the returns. For chemicals and instruments, the social return exceeded the private return by approximately 30 and 35 percent, respectively. Machinery exhibited the smallest differential which amounted to about 10 percent. Yet in the petroleum industry the social rate exceeded the private rate by more than 75 percent.

Empirical work relating to R\&D spillovers is only beginning. There are many avenues to pursue in order to extend the results obtained in this paper. One of the more important directions is to introduce interindustry spillovers. There are many situations where industries do not transact with each other, through input purchases for example, but do "borrow" each other's knowledge capital. Two industries which fit this situation may be telecommunications and computers. Another important extension is to the realm of international $R \& D$ spillovers. Indeed there is significant knowledge diffusion through spillovers between Japan and the United States, Europe and the United States, and the economies in North America. 
FOOTNOTES

* The authors would like to thank Graham Corke for his research assistance. We would also like to thank Michael Denny, Erwin Diewert, Mel Fuss, Zvi Griliches, Ariel Pakes, Rick Levin, and the members of the NBER productivity group for many helpful comments and suggestions. Financial support was provided by the NSF grant PRA-8108635. Technical assistance provided by the C.V. Starr Center for Applied Economics is also gratefully acknowledged. This paper is the extended and revised version of our paper entitled "Research and Development, Spillover and Adjustment Costs: An Application at the Firm Leve1."

1 All variables are defined as non-negative real numbers. $L(t), I_{p}(t)$, $I_{r}(t)$ are piecewise continuous functions of $t$ (which denotes the time period) and $K_{p}(t)$, and $K_{r}(t)$ (and thereby also $X_{r}(t)$ ) are continuous functions of $t$ with piecewise continuous first derivatives. In addition, from this point onward in the paper the ( $t$ ) notation is excluded unless ambiguity arises. 2 In the few empirical studies on R\&D spillovers that are available the effects of $R \& D$ spillovers on non-R\&D capital inputs are assumed away because production and R\&D activities are deemed to be separable [see Evenson and Kislev (1973), Levin and Reiss (1984), and Jaffe (1984, 1985)].

3 If the own and borrowed $R \& D$ capital stocks are perfect substitutes then we can define $A_{r}=K_{r}+\theta X_{r}=K_{r}+\theta \Sigma_{f} K_{r}^{f}$. Now R\&D capital accumulates as $\dot{\mathrm{A}}_{\mathrm{r}}=\dot{\mathrm{K}}_{\mathrm{r}}+\theta \Sigma_{\mathrm{f}} \dot{\mathrm{K}}_{\mathrm{r}}^{\mathrm{f}}=\mathrm{I}_{\mathrm{r}}-\delta_{\mathrm{r}} \mathrm{K}_{\mathrm{r}}+\theta \Sigma_{\mathrm{f}}\left(\mathrm{I}_{\mathrm{r}}^{\mathrm{f}}-\delta_{\mathrm{r}} \mathrm{K}_{\mathrm{r}}^{\mathrm{f}}\right)$. By the definition of $\mathrm{K}_{\mathrm{r}}$, R\&D capital accumulation can be written as $\dot{A}_{r}=I_{r}+\theta \Sigma_{f} I_{r}^{f}-\delta_{r} A_{r}$. In the case of perfect substitutes, knowledge accumulates by the R\&D investment of the firm and the spillover associated with the R\&D investment of other firms 
in the economy.

4 The present value of normalized costs is formulated in terms of the state variables, rather than the controls, due to the fact that the problem can be transformed by applying integration by parts.

5 The discount rate is assumed to be constant. This simplifies the empirical implementation of the model. In empirical dynamic models with more than one quasi-fixed factor, it is customary to assume that the discount rate is constant in order to obtain reduced form equations [see Epstein and Yatchew (1985)] or to use instrumental variable estimation [see Hanson and Singleton (1982)] .

6 Since there is a single variable factor of production then variable factor demand is equivalent to normalized variable costs.

7 The extent to which R\&D capital spill over and affects the structure of production is parameterized by $a_{0}, c_{1}$ and $c_{2}$ in the value function. The spillover parameter $(\theta)$ is implicitly defined through this parameterization, as we can consider $a_{0}=\alpha_{0} \theta$, and $c_{i}=\xi_{i} \theta, i=1,2$, where $\alpha_{0}, \xi_{i}$, and $\xi_{2}$ are also parameters.

8 The error term in the variable factor demand equation (9.1) can also reflect technology stocks. However, if the error terms in (9.2) are to represent technology stocks, then the error term in (9.1) must be correlated with the normalized rental rates which would complicate the estimation of the model.

9 The speed at which physical capital adjusts in the manufacturing sector, as estimated by Berndt, Fuss and Waverman (1979) (which was 3.3 years) and by Morrison and Berndt (1981) (which was 3.7 years) are similiar to our results. Using dynamic duality, Epstein and Denny found that capital takes 8.3 years to adjust in the manufacturing sector. The models, however, are not strictly comparable. 

variable costs. Hence the elasticity $e_{l \theta}^{\mathbf{s}}$ is the R\&D spillover elasticity of normalized variable costs.

11 In defining (14) we have used the fact that $J_{K}^{T}=\left(J_{p} J_{r}\right)$ in equation (5) is equal to $\left(\omega^{T} A_{w K}+a^{T}\right)$ using the specification of the value function from (8).

12 The discount rate to a firm $(\rho)$ is the private net of depreciation real rate of return on $R \& D$ capital. The industry's discount rate $(\gamma)$ is the social net of depreciation real rate of return on R\&D capital. The industry's return is the social return because all externalities associated with R\&D capital are internalized by the industry. 


\section{REFERENCES}

Arrow, K., and M. Kurz. (1970). Public Investment, the Rate of Return and Optimal Fiscal Policy, Baltimore: Johns Hopkins Press.

Benveniste, L.M., and J.A. Scheinkman. (1979), "Differentiable Value Functions in Concave Dynamic Optimzation Problems", Econometrica, 47, 727-732.

Berndt, E.R., M. Fuss and L. Waverman. (1979). A Dynamic Mode1 of Cost of Adjustment and Interrealted Factor Demands", Institute for Policy Analysis, University of Toronto.

Cohen, W. and D. Levinthal. (1986). "The Endogeneity of Appropriability and R\&D Investment", mimeo.

Cummins, Clint, Bronwyn H. Hall and Elizabeth S. Laderman. (1982). "The R\&D Master File", National Bureau of Economic Research.

Dreyfus, S.E. (1965). Dynamic Programming and the Calculus of Variation, New York: Academic Press.

Epstein, L.G. (1981). "Duality Theory and Functional Forms for Dynamic Factor Demands", Review of Economic Studies, 48, 81-95.

Epstein, L., and M. Denny. (1983). "The Multivariate Flexible Accelerator Model: Its Empirical Restriction and Application to U.S. Manufacturing", Econometrica, $51,647-674$.

Epstein, L.G., and A.J. Yatchew. (1985). "The Empirical Determination of Technology and Expectations: A Simplified Procedure", Journal of Econometrics, 27, 235-258.

Evenson, R.E., and Y. Kislev. (1973). "Research and Productivity in wheat and Maize", Journal of Political Economy, 81, 1309-1329.

Griliches, Z. (1979). "Issues in Assessing the Contribution of Research and Development to Productivity Growth", Bell Journal of Economics, Spring, $92-116$. 
Hansen, L.P., and K.J. Singleton. (1982). "Generalized Instrumental Variables Estimation of Nonlinear Rational Expectations Models", Econometrica, 50, $1269-1286$.

Jaffe, A. (1984). "The Effects of Market Demand, Technological Opportunity and Research Spilloevers on R\&D Intensity and Productivity Growth", mimeo.

. (1985). "Technological Opportunity and Spillovers of R\&D: Evidence from Firms' Patents, Profits and Market Value," mimeo.

Lau, L. (1976). "A Characterization of the Normalized Restricted Profit Function", Journal of Economic Theory, 12, 131-163.

Levin, R.C., and P.C. Reiss. (1984). "Tests of a Schumpsterian Mode1 of R\&D and Market Structure", in Z. Griliches (ed.), R\&D, Patents and Productivity, National Bureau of Economic Research, Chicago, I11.: University of Chicago Press.

Mansfield, E. et al. (1977). "Social and Private Rates of Return from Industrial Innovations". Suarterly Journal of Economics, 77, 221-240.

Mclaren, K., and R. Cooper. (1980). "Intertemporal Duality: Application to the Theory of the Firm", Econometrica, 48, 1755-1762.

Morrison, C., and E. Berndt. (1981). "Short-run Labor Productivity in a Dynamic Model", Journal of Econometrics, 16, 339-365.

Mortensen, D. (1973). "Generalized Costs of Adjustment and Dynamic Factor Demand Theory", Econometrica, 41, 657-666.

Mowery, D.C. (1983). "The Relationship Between Intrafirm and Contractrual Forms of Industrial Research in American Manufacturuing, 1900-1940, ", Explorations in Economic History.

Nelson, R.R. (1982). "The Role of Knowledge in R\&D Efficiency", Quarterly Journal of Economics. 97, 453--470. 
Reinganum, J.F. (1981). "Dynamic Games of Innovation", Journal of Economic Theory, 25, 21-41.

Rockafeller, R.T. (1970). "Conjugate Convex Functions in Optimal Control and the Calculus of Variations", Journal of Mathematical Analysis and Applications, 32, 411-427.

Spence, A.M. (1984). "Cost Reduction, Competition and Industry Performance", Econometrica, 52, 101-121.

Treadway, A. (1974). "The Globally Optimal Flexible Accelerator", Journal of Economic Theory, 7, p. 17-39.

(1971). "The Rational Multivariate Flexible Accelerator", Econometrica, $39,845-856$. 